Maria Antónia Coutinho, Noémia Jorge

Universidade Nova de Lisboa, CLUNL, FCT

\title{
Géneros de texto e construção discursiva do tempo*
}

Palavras-chave: géneros de texto, tipos de discurso, ordem do expor, ordem do narrar

\section{Enquadramento geral}

O presente trabalho situa-se na perspetiva da Teoria do Texto - área disciplinar que se enraíza no campo da linguística, mais especificamente, no campo da linguística dos textos e dos discursos, e privilegia, de forma particular, o quadro designado por Jean-Paul Bronckart (Bronckart, 1999) como Interacionismo Sociodiscursivo (daqui para a frente, ISD).

Não cabe neste espaço desenvolver todos os aspetos que configuram, teórica e epistemologicamente, a especificidade do ISD - que se constitui na continuidade do paradigma interacionista social, decisivamente marcado pelas contribuições de Vygotski ([1934] 1997) e de Voloshinov ([1929] 1977), radicalizando, se assim se pode dizer, a preocupação e o interesse em torno do papel da linguagem, enquanto fenómenos psico-sócio-semióticos, tanto nas fases precoces do desenvolvimento da criança como no desenvolvimento da pessoa, ao longo da vida. No presente contexto, sublinharemos o facto de os textos serem entendidos, no ISD, como ações comunicativas globais que acontecem no âmbito de uma prática social determinada - não sendo redutíveis, portanto, a um objeto (ou a uma abordagem) estritamente linguístico(a). Como claramente mostrou Voloshinov ([1929] 1977), as práticas sociais elaboram, sustentam e transformam formatos ou modelos para as práticas de linguagem que nelas acontecem. Cada atividade social dispõe assim, em cada época, de forma mais ou menos maleável,

* Este texto foi redigido em Português Europeu, conforme o Acordo Ortográfico da Língua Portuguesa em vigor. Optou-se por preservar a grafia original das citações. 
de um conjunto de formas comunicativas a que chamamos géneros de texto - que, no dizer de Bronckart, se apresentam aos utentes da língua sob a forma de nebulosa (onde coexistem géneros estabilizados e conjuntos de textos sem fronteiras fixas ou nítidas). Neste sentido, cada texto efetivamente realizado (ou a realizar) depende de um género, selecionado de entre os géneros associados à atividade em causa, numa época dada, mas também de entre os géneros de que o agente dispõe, como modelos interiorizados através da experiência textual que é a sua. Se o género projeta assim sobre o texto um conjunto de determinações sociais, importa também ter em conta as especificidades da língua em uso. Assim, a produção de um texto (entendido como ação comunicativa) resulta de um funcionamento em interface, articulando o conhecimento da situação, o conhecimento do sistema (maleável) dos géneros de texto e o conhecimento da língua (Bronckart, 1999: 108).

$\mathrm{Na}$ perspetiva assumida no quadro do ISD, há ainda a considerar uma plataforma organizacional intermédia, entre os textos efetivamente produzidos e os recursos linguísticos neles mobilizados. Esse nível organizacional é o dos discursos (ou tipos de discurso) - compreendidos como segmentos infra-ordenados que entram na composição dos textos (correspondendo estes, por sua vez, a unidades comunicativas globais, como já foi referido). Assim, e na continuidade de posicionamentos anteriores Benveniste (1966), Weinrich (1973), Simonin-Grumbach (1975), Genette (1986) - os discursos correspondem a atitudes de locução, ou modos de enunciação que se configuram como envelopes de unidades linguísticas e entram na constituição dos textos, como segmentos identificáveis por essas mesmas unidades linguísticas.

A forma como se constituem diferentes tipos de discurso pode ser descrita tendo em conta dois tipos de rutura. Em primeiro lugar, uma rutura de ordem temporal: ou se verifica correspondência entre as coordenadas temporais da ação de linguagem, no mundo vulgar do agente, e as que são verbalizadas no texto (relação de conjunção) ou, pelo contrário, existe rutura entre essas mesmas ordens de coordenadas (relação de disjunção). No primeiro caso, estamos na ordem do expor, enquanto o segundo caso é da ordem do narrar. Estas duas ordens discursivas podem ver-se ainda desdobradas, se fizermos intervir uma segunda rutura, de ordem actorial: ou se verifica correspondência entre as instâncias responsáveis pela ação de linguagem e as que são verbalizadas no texto (relação de implicação) ou, pelo contrário, existe rutura entre elas (relação de autonomia). Podemos assim considerar, no cruzamento destas 
duas ordens de operações, quatro possibilidades, como mostra o Quadro n. $^{\circ} 1$, adaptado de Bronckart (2008: 71), que a seguir se apresenta:

\begin{tabular}{|c|c|c|c|}
\hline & \multicolumn{2}{|c|}{$\begin{array}{l}\text { Organização temporal } \\
\text { (relação entre as coordenadas temporais } \\
\text { dos processos verbalizados no texto e as } \\
\text { coordenadas temporais da situação de produção) }\end{array}$} \\
\hline & & Conjunção & Disjunção \\
\hline & & Ordem do EXPOR & Ordem do NARRAR \\
\hline \multirow{2}{*}{\begin{tabular}{|c|} 
Organização actorial \\
(relação entre as instâncias \\
de agentividade mobilizadas \\
no texto e as instâncias de \\
agentividade associadas à \\
situação de produção)
\end{tabular}} & Implicação & Discurso interativo & Relato interativo \\
\hline & Autonomia & Discurso teórico & Narração \\
\hline
\end{tabular}

\section{Quadro n. $^{\circ} 1$}

Se cada tipo de discurso se configura (e se deixa reconhecer) pelas unidades linguísticas em ocorrência, importa sublinhar que uma ou outra unidade não chega para esse processo: é o conjunto das unidades em coocorrência que dá forma (semiotiza) uma atitude (discursiva). É o que pretende mostrar o Quadro 2, em que se evidenciam algumas características linguísticas predominantemente associadas aos quatro tipos de discurso. Como se pode verificar, a ocorrência de deíticos, por exemplo, não chega para identificar um determinado tipo de discurso - que se reconhece, no entanto, na coocorrência com outras formas, nomeadamente, os tempos gramaticais.

\begin{tabular}{|c|c|}
\hline $\begin{array}{l}\text { Deíticos } \\
\text { Formas verbais no presente do indicativo } \\
\text { com valor deítico } \\
\ldots \\
\text { Discurso interativo }\end{array}$ & $\begin{array}{l}\text { Deíticos } \\
\text { Localizadores temporais (deíticos) } \\
\text { Formas verbais no pretérito perfeito } \\
\text { simples e imperfeito } \\
\text { Relato interativo }\end{array}$ \\
\hline $\begin{array}{l}\text { Ausência de deíticos } \\
\text { Formas verbais no presente do indicativo teórico } \\
\text { com valor gnómico } \\
\text { Conectores argumentativos e outros } \\
\text { organizadores textuais } \\
\ldots\end{array}$ & $\begin{array}{l}\text { Narração } \\
\text { Ausência de deíticos } \\
\text { Localizadores temporais (não deíticos) } \\
\text { Formas verbais no pretérito perfeito } \\
\text { simples e imperfeito } \\
\ldots\end{array}$ \\
\hline
\end{tabular}

\section{Quadro n. ${ }^{\circ} 2$}

$\mathrm{Na}$ necessária interrelação psico-sócio-semiótica que, na conceção do ISD, caracteriza as práticas de linguagem, os tipos de discurso desempenham um papel fundamental: eles são, por um lado, a condição e o lugar de elaboração de 
raciocínios diferenciados (cronológico-temporais, nos discursos da ordem do narrar; práticos, no discurso interativo; lógicos ou quase-lógicos, no discurso teórico); por outro, na medida precisamente em que se constituem como capacidades (de linguagem e de pensamento), eles viabilizam a transição entre as representações individuais, enraizadas na experiência vivida de cada pessoa, e as representações coletivas, estabilizadas pelas instâncias sociais e pelas obras da cultura ( $c f$. a este propósito Bronckart, 2008: 90). A centralidade que assim se atribui aos tipos de discurso manifesta-se ainda, operacionalmente, pelo facto de se assumir que eles entram obrigatoriamente na constituição de qualquer texto, oral ou escrito (na medida em que não é possível deixar de assumir uma ou outra atitude discursiva).

\section{Hipótese de trabalho}

É sobre oúltimo aspeto referido que se centra a nossa investigação - prolongando uma pista de reflexão e de trabalho que se pode considerar em curso, no âmbito do ISD ${ }^{1}$. Assumindo, como vem sendo exposto, a inevitabilidade dos tipos de discurso, na produção linguística, o ISD mantém também a (relativa) estabilidade dos mesmos (sem a qual, de resto, não faria sentido considerálos como tipos): assim, e ao contrário da extrema diversidade e flexibilidade dos géneros de texto (e também, consequentemente, dos textos empíricos), os tipos de discurso são dotados de regularidades sintático-semânticas, tendo em conta a especificidade própria de cada língua. Subscrevendo inteiramente esta conceção, parece no entanto haver espaço para questionamento - e investigação, portanto. Efetivamente, se os tipos de discurso entram na constituição de qualquer texto, como já vimos, e se os géneros funcionam como modelos (mais ou menos flexíveis e plásticos) para a produção (e a interpretação) dos textos, a pergunta que se pode colocar é a seguinte: há algum tipo de relação que se possa estabelecer - de forma mais ou menos previsível - entre atividades, géneros, textos empíricos e tipos de discurso? Em termos mais concretos: no âmbito de determinada atividade e selecionado um determinado género, há alguma regularidade que se possa observar entre o(s) texto(s) produzido(s) e os tipos de discurso que entram na constituição desse(s) texto(s)?

Este questionamento vem sendo desenvolvido no âmbito do grupo de investigação em que nos integramos ${ }^{2}$. Por um lado, retomando Coutinho

1 O trabalho beneficia também da investigação realizada no âmbito do plano de trabalhos de doutoramento de N. Jorge, sob orientação de M. A. Coutinho, intitulado «O género 'memórias'. Análise linguística e perspetiva didática» e financiado pela FCT (SFRH / BD / 61301 / 2009).

Projeto Pretexto - Praxis, Conhecimento e Texto, desenvolvido no âmbito do grupo Gramática 
\& Miranda (2009), podemos sublinhar a necessidade de articulação entre a noção de género de texto, como modelo, e o modelo de produção textual, tal como tem sido pensado no ISD: definindo-se o género, inequivocamente, por fatores contextuais (físicos e sociosubjetivos), parece estranho que nenhuma implicação daí decorra, no que diz respeito aos aspetos organizacionais do texto produzido/a produzir (aspetos esses normalmente referidos como arquitetura textual, no quadro do ISD). Na continuidade, aliás, da abordagem descendente que decorre dos pressupostos epistemológicos assumidos, faz sentido pensar que a atividade e o género projetam determinações discursivas (e linguísticas) sobre a confeção do texto empírico. Resta saber se há alguma regularidade que se possa identificar, desse ponto de vista. Uma resposta tendencialmente afirmativa tem sido sustentada por Miranda (2009), que mostrou como um mesmo tipo de discurso pode aparecer de forma diferenciada em textos de diferentes géneros. Por outras palavras: de acordo com os géneros em que ocorre, um tipo de discurso «mostra especificidades no plano da configuração do tipo linguístico» (Miranda, 2009: 366).

Finalmente, importa ainda reter algumas das pistas e sugestões de trabalho apontadas por Bronckart (2008), corroborando o interesse desse tipo de questionamento e admitindo a possibilidade de se verificarem «restrições de seleção discursiva» em diferentes géneros de texto: «en d'autres termes, on pourrait et devrait examiner dans quelle mesure un type discursif est «possible» ou non dans un genre donné, ainsi que les formes de distribution et d'articulation de types qui seraient propres à un genre» (Bronckart, 2008: 86). Retomando perspetivas já anteriormente apontadas sobre modalidades de articulação dos tipos de discurso, o autor explicita o interesse de levar por diante a análise dessas mesmas modalidades, numa perspetiva de caracterização dos géneros.

Mais il semble en outre que l'on puisse distinguer, dans les textes relevant d'un même genre, d'une part un type de discours dominant ou majeur, et d'autre part des types de discours dominés ou mineurs ( $c f$. . ATD, pp.); distinction qui ne se fonde pas nécessairement sur la taille respective de ces types (sur une comparaison de leur longueur), mais surtout sur un examen des modalités linguistiques de leurs articulations, qui fait apparaître que certains types sont manifestement «enchâssés»

\& Texto do CLUNL - Centro de Linguística da Universidade Nova de Lisboa (mais informação disponível em http://www.clunl.edu.pt/PT/projeto.asp?id=770\&mid=138). 
dans d'autres. Ce type d'examen est aussi à développer, dans la même perspective de contribution à la caractérisation des genres. (Bronckart, 2008: 86-87)

É na continuidade das pistas apontadas que se situa o presente trabalho. Assumindo que os tipos de discurso entram (obrigatoriamente) na constituição de qualquer texto (oral ou escrito), como já atrás dissemos, pretendemos averiguar em que medida a atividade social e o género de texto condicionam o recurso ou a integração de diferentes tipos de discurso.

\section{Relação entre atividades, géneros e tipos de discurso}

Através da análise de dois textos memorialísticos e de dois textos de divulgação científica, procuraremos perspetivar (algumas das) relações entre atividades, géneros e tipos de discurso, nos casos em análise. De forma mais específica, centrar-nos-emos sobre a distinção entre a ordem do expor e a ordem do narrar, enquanto modos de construção discursiva do tempo - identificando o papel dessa mesma construção na configuração dos textos em análise.

\subsection{Análise de dois textos do género memórias}

O primeiro exercício de análise textual tem como base a comparação de dois excertos pertencentes a dois textos memorialísticos distintos:

- Texto 1. A: As minbas memórias, João Manuel Azenha;

- Texto 1. B: As pequenas memórias, José Saramago.

O Texto 1. A. foi escrito por João Manuel Azenha entre 2006 e 2007. Trata-se de um texto autobiográfico inédito produzido pelo autor aos 76-77 anos de idade, sem pretensões literárias, com o intuito de dar a conhecer/preservar o seu percurso existencial, enraizado no contexto rural de uma aldeia portuguesa (Alvarinhos, Sintra), entre 1930 e 2007. O autor fez exame da $3^{\text {a classe em }}$ 1942 - tendo então concluído o percurso de escolarização. Tendo em conta o respetivo contexto de produção, circulação e receção, é legítimo concluir que este texto se encontra circunscrito à atividade familiar.

O Texto 1. B. foi escrito por José Saramago (Prémio Nobel da Literatura) e publicado pela Editorial Caminho em 2006. Ainda que outras atividades possam estar subjacentes à sua produção (como a editorial e mesmo a familiar), este texto encontra-se inequivocamente inscrito no âmbito da atividade literária (articulada com a atividade editorial). 
Produzidos em atividades diversas e com objetivos distintos, os dois textos apresentam, contudo, regularidades temáticas e discursivas que permitem considerá-los como pertencentes ao género textual memórias. Em traços gerais, este género pode ser caracterizado por uma enunciação ulterior e retrospetiva de acontecimentos passados, focando tematicamente a articulação entre a vida individual do agente produtor e o respetivo contexto histórico-cultural. Consequentemente, tal como acontece em outros géneros autobiográficos, verifica-se a convergência de identidade entre autor/produtor, enunciador discursivo e personagem ${ }^{3}$. No âmbito dos estudos literários, Rocha (2006: 628) aponta ainda como traço definitório do género o papel desempenhado pela memória, ou seja, a «recriação selectiva do passado cujos pormenores se foram apagando por força da inexorável amnésia que ao longo da vida vai filtrando as recordações, ou que pelo contrário se fixaram como marcos ou nós obsessivos de um percurso vital». Enunciação retrospetiva e memória assumem-se, assim, como noções de charneira no que se refere à construção discursiva do tempo em textos que adotam o género memórias, independentemente dos objetivos e das atividades que subjazam à sua produção.

Com efeito, em termos discursivos, em ambos os textos se verifica a articulação entre duas atitudes distintas de locução, subsequentes do facto de a enunciação ser feita de forma retrospetiva:

- por um lado, por meio do relato interativo, contam-se/relatam-se factos passados (estabelecendo-se uma relação de disjunção entre o mundo real e o mundo representado);

- por outro lado, através do discurso interativo, mostram-se/expõem-se factos presentes (estabelecendo-se uma relação de conjunção entre o mundo real e o mundo representado).

Uma análise comparativa de dois excertos pertencentes aos textos em causa demonstrará que as características discursivas que estruturam temporalmente os dois textos são semelhantes. Com efeito, em ambos se verifica a articulação entre o relato de acontecimentos passados e a exposição de acontecimentos presentes, como o demonstra o Quadro n. $^{\circ} 3$ :

3 Não problematizaremos neste momento questões relacionadas com o grau de ficcionalidade que se pode imprimir a cada um dos textos em análise. No entanto, assumindo que qualquer produção linguística tem uma função representativa, parece-nos legítimo afirmar que o cálculo associado ao grau de ficcionalidade é condicionado pela atividade em que o género é produzido. 
Excerto do texto 1. A

\begin{tabular}{|l|}
\hline Ordem do expor \\
\hline Desde criança que sempre me lembro \\
\begin{tabular}{l} 
Ordem do narrar \\
\hline de me chamarem esse nome ao ponto \\
de que em Alvarinhos quase ninguém \\
me conhecia pelo nome de João \\
Azenha. Mas sim por Laró ou Laró- \\
Velho. Com oito anos vim morar para \\
Santa Suzana. Então aqui a princípio \\
as pessoas chamavam-me João, mas \\
depois passado algum tempo quase \\
todos me chamavam novamente Laró. \\
Alcunha que só depois de eu ter mais \\
de vinte anos começou a desaparecer \\
aos poucos.
\end{tabular} \\
\hline \\
Hoje só por brincadeira me chamam \\
Laró, «a qual eu acho uma certa graça». \\
\hline
\end{tabular}

Excerto do texto 1. B

\begin{tabular}{|l|}
\hline Ordem do expor \\
\hline Lembro-me \\
\hline Ordem do narrar \\
\hline $\begin{array}{l}\text { de que este tio aparecia de vez em } \\
\text { quando com um coelho ou uma } \\
\text { lebre, espingardeados durante as } \\
\text { suas voltas pela herdade. Para ele, } \\
\text { que era guarda, o defeso devia ser } \\
\text { uma palavra vã. Um dia chegou a } \\
\text { casa triunfante como um cruzado } \\
\text { que viesse de desbaratar um exército } \\
\text { de infiéis. Trazia uma grande ave } \\
\text { dependurada do arção, uma garça } \\
\text { cinzenta, bicho novo } \\
\text { para mim e que } \\
\text { era proibido matar. Tinha uma carne } \\
\text { tirante a escura, com ligeiro gosto a } \\
\text { peixe, } \\
\text { se é que não estarei agora, depois de } \\
\text { tantos anos, a sonhar com sabores } \\
\text { que nunca me afagaram o paladar } \\
\text { nem passaram pela goela. }\end{array}$ \\
\hline
\end{tabular}

\section{Quadro n. ${ }^{\circ} 3$}

Nos exemplos em análise a exposição de acontecimentos presentes está diretamente relacionada com o ato de rememorar característico do género memórias. Assumindo-se como moldura explícita do mundo representado, esse ato constrói-se discursivamente pelas formas verbais lembro (Texto 1. A e Texto 1. B) e desconfio (Texto 1. B), no presente do indicativo. O momento da enunciação é reforçado, no final dos dois textos, não só pela exploração de formas verbais de presente (chamam e acho - Texto 1. A) ou de futuro com valor de presente (estarei ${ }^{4}$ - Texto 1. B), como também pela presença de unidades deíticas que remetem para o tempo da enunciação, nomeadamente os advérbios boje (Texto 1. A) e agora (Texto 1. B).

Por seu turno, o mundo representado encontra-se discursivamente estruturado com base na exploração do subsistema de tempos característicos da ordem do narrar - tempos esses já assinalados por Benveniste (1966) como associados

4 A ocorrência do futuro não está neste caso associada a um valor temporal, marcando antes um valor modal epistémico. 
ao plano da bistória e designados por Weinrich como tempos narrativos (1973). Constatamos assim a ocorrência do pretérito perfeito simples (vim - Texto 1. A; chegou - Texto 1. B) - por vezes conjugado perifrasticamente (começou a desaparecer - Texto 1. A) em articulação com o pretérito imperfeito (conbecia, chamavam - Texto 1. A; aparecia, era, trazia, tinba - Texto 1. B). A corroborar estas ocorrências, há ainda a presença de organizadores temporais que constroem o narrar a partir de uma origem temporal autónoma distinta do momento da enunciação (com oito anos, então, depois, passado algum tempo, depois de eu ter mais de vinte anos - Texto 1. A; de vez em quando, um dia - Texto 1. B). Embora os dois textos em análise apresentem inegáveis regularidades ao nível da construção discursiva do tempo, não se pode afirmar que as atividades em que estes se inserem não exerçam qualquer influência a este nível. Com efeito, verifica-se no Texto 1 . B uma maior conceptualização sobre o ato de narrar do que no Texto 1. A, facto que se repercute na complexidade dos mecanismos linguísticos utilizados na textualização do tempo - em especial no que se refere à interação entre o tempo da história e o tempo da enunciação; destaque-se, a este nível, a intrusão da forma verbal desconfio no interior do discurso relatado, desnecessária em termos sintáticos, mas com um claro efeito estilístico; destaque-se ainda o processo de articulação os dois tipos de discurso, no final do texto (a opção pela coesão interfrásica, conseguida pela subordinação condicional, poderá ser encarada como um processo facilitador da interação entre o passado factual e o presente hipotético/reflexivo). A predominância do pretérito imperfeito (em detrimento do pretérito perfeito simples) poderá evidenciar também um determinado grau de elaboração intelectual, na medida em que, em vez de relatar um acontecimento pontual, o enunciador opta por marcar a iteratividade da situação selecionada.

Não quer isto dizer que o Texto 1 . A esteja totalmente isento de elaboração intelectual ou de distanciamento sobre o ato de narrar. Com efeito, tal como acontece no Texto 1. B, também aqui o enunciador marca, ainda que em menor grau, a distinção entre o mundo real e o mundo representado, posicionandose no momento presente. A prová-lo está, por exemplo, o segmento Com oito anos vim morar para Santa Suzana. Então aqui a princípio as pessoas... - nele a forma verbal vim e o advérbio aqui assumem um valor deítico, remetendo para o momento presente. A interação passado-presente verifica-se ainda na expressão que introduz o excerto (Desde criança que sempre me lembro), sendo que o localizador temporal Desde criança atribui ao verbo lembrar uma origem temporal passada que se prolonga até ao presente. 
Em suma, nos textos memorialísticos analisados verifica-se a articulação entre duas atitudes distintas de locução (dois tipos de discurso): ora se contam/ relatam factos passados, recorrendo ao relato interativo, ora se mostram/ expõem factos presentes, recorrendo ao discurso interativo. Recuperando o pressuposto atrás apresentado - de que nos textos que adotam o mesmo género há, por um lado, um tipo de discurso dominante/maior e, por outro, tipos de discurso dominados/menores (Bronckart, 2008: 86-87), a questão que se coloca neste momento é a de saber se a relação que se estabelece entre o narrar implicado e o expor implicado é, efetivamente, de subordinação. Em caso afirmativo, outras questões se poderão impor. Qual é, nestes excertos textuais, o discurso dominante/maior? O discurso interativo, que se assume como moldura do relato interativo, ou o relato interativo que, apesar de se encontrar encaixado no discurso interativo, se destaca nitidamente em termos de extensão? Que tipo de raciocínio prevalece nestes excertos textuais - o cronológico temporal (explorado pelo relato interativo), ou o prático (explorado pelo discurso interativo)? Parecenos que, relativamente aos textos empíricos em análise, a articulação entre as duas atitudes de locução se faz por meio de um processo de emolduramento (e não de subordinação); esse processo, que configura linguisticamente a imbricação entre o passado (tempo do mundo representado) e o presente (tempo do mundo representado e do mundo real), poderá ser encarado como um parâmetro do género memórias.

\subsection{Análise de dois artigos da revista Colóquio/Ciências}

Propomo-nos agora observar dois textos do mesmo género, associados a uma mesma atividade: trata-se de artigos científicos (ou de divulgação científica) disponíveis na revista Colóquio/Ciências:

- Texto 2. A: «As fosfatases e a linguagem intracelular»;

- Texto 2. B: «Catálise e catalisadores».

Publicada pela Fundação Calouste Gulbenkian entre 1988 e 2000, a revista Colóquio/Ciências integra-se na atividade científica, envolvendo diferentes áreas de conhecimento. $\mathrm{Na}$ prática, trata-se de uma modalidade que se cruza necessariamente com características, interesses ou imposições de outras áreas. Em primeiro lugar, poderá tomar-se como praticamente consensual a articulação científico-académica - corroborada pela garantia, em «Nota de abertura» no primeiro número5 ${ }^{5}$ de todos os artigos serem assinados

5 A «Nota de abertura» é assinada por João Andrade e Siva, diretor da revista (Silva, 1988). 
por «cientistas autênticos», isto é, nomes de referência nas áreas em causa, frequentemente associados ao ensino e à investigação em universidades portuguesas. Mais importante ainda é a orientação que importa atribuir ao subtítulo da revista - a saber, Revista de Cultura Científica. Com efeito, ele está diretamente associado à finalidade que a revista assume e que a mesma «Nota de abertura» também explicita: proporcionar ocasião de desenvolvimento de cultura científica. Antecipam-se de imediato, no entanto, as dificuldades que essa finalidade poderá encontrar, curiosamente decorrentes do perfil de «cientistas autênticos» dos autores convocados - a privilegiar afinal, como destinatário, um público relativamente especializado:

Enfim, e para garantia do leitor, queremos assegurar-lhe, desde já, que «Colóquio-Ciências» só publicará artigos de cientistas autênticos, gente com um conhecimento vivido dos temas de que se ocupa. Não é fácil o que se lhes requere, apresentar de forma simples um saber assimilado na sua complexidade intrínseca, tanto mais que há sempre a manter um delicado equilíbrio entre simplicidade e rigor. Seja pois o leitor paciente e corajoso quando, aqui e além, se lhe deparar um texto que seja, ou que se lhe afigure, mais difícil de entender. (Silva, 1988: 2)

Ainda que o grande público possa, portanto, encontrar dificuldades consideráveis, será legítimo considerar que a atividade científica (ou científico-académica) se reconfigura aqui parcialmente, dentro dos limites apontados, como atividade de divulgação científica. Finalmente, importa também considerar a atividade editorial que, inequivocamente, determinará a formatação e paginação dos textos, bem como as respetivas condições de leitura e de circulação.

Os aspetos até agora apontados proporcionam uma caracterização geral dos textos em análise, no que diz respeito ao contexto sócio-subjetivo que lhes está associado: é em função das finalidades e dos perfis dos interlocutores, enquanto 'entidades' socialmente posicionadas, que podemos reconhecer o género em causa. Assumiremos tratar-se, neste caso, de textos do género artigo de cultura cientifica - condensando nesta fórmula a convergência entre o carácter inequivocamente científico e uma finalidade de divulgação (que tendencialmente não atinge o grande público $)^{6}$. A questão que nos interessa

6 A designação de um género é reconhecidamente uma questão menor, do ponto de vista teórico; no limite, podem circular géneros de texto para os quais não se reconhecem 
agora verificar é a seguinte: os fatores contextuais identificados terão alguma consequência, em termos de organização discursiva? $\mathrm{Ou}$, de forma mais específica: haverá alguma regularidade, na seleção e disposição de discursos estabelecidos em função de critérios temporais diferenciados (ordem do expor / ordem do narrar)?

Tendo em conta que se trata de artigos relativamente longos, optámos por limitar a análise a excertos previamente identificados nos dois textos: os blocos iniciais, delimitados entre o título (e o resumo) e o primeiro intertítulo ( $c f$. Anexos, onde se reproduzem as primeiras páginas dos artigos em causa). A natureza académica (ou académico-científica) atrás referida permite prever que a adoção do género não seja meramente inconsciente ou casual. Nesse sentido, os blocos recortados para análise coincidirão, em princípio, com introduções retórica e/ou academicamente previsíveis ou mesmo exigidas.

O Texto 2. A. exibe quase de forma exemplar as características do discurso teórico - como se poderá observar no Quadro n. ${ }^{\circ} 2$ (apesar de, por razões de espaço, não ser possível mostrar todo o excerto em causa). Observa-se assim a ocorrência de formas verbais no presente do indicativo com valor atemporal (ou gnómico), estruturas passivas, recurso a organizadores textuais e a exemplificação, recorrência de estruturas anafóricas (que marcam a continuidade intratextual). Como também mostra o Quadro n. ${ }^{\circ}$ 2, verifica-se uma brevíssima ocorrência de disjunção temporal - assinalada pelo localizador temporal e pela ocorrência de um pretérito perfeito simples. O valor deítico do localizador temporal marca o carácter implicado do relato interativo. Ao mesmo tempo, a construção passiva (truncada, isto é, sem explicitação de agente da passiva) parece corresponder a uma espécie de contaminação provocada pelo discurso teórico - claramente dominante no excerto.

designações estáveis ou fixas. 


\section{Ordem do expor}

O termo transdução de sinais refere-se à transferência de informação através da membrana celular, isto é, à detecção de um sinal extracelular, respectiva transformação noutro sinal intracelular, e sua propagação. A transdução de sinais é um componente essencial da regulação celular. Por exemplo, várias moléculas bioactivas, das quais as hormonas e os neurotransmissores são os exemplos melhor conhecidos, estão acopladas às suas vias de sinalização intracelular através de receptores membranares (Fig. 1). As cascatas de sinalização são iniciadas por primeiros mensageiros (hormonas, neurotransmissores ou drogas, por exemplo) que passam a sua informação ao compartimento intracelular através de receptores membranares que, por sua vez, levam à produção de segundos mensageiros (por exemplo, cálcio e cAMP). [...] $\mathrm{O}$ tipo de receptores membranares que uma dada célula expressa, num determinado espaço temporal, define as moléculas capazes de desencadear uma resposta celular. Por outro lado, a natureza dessa resposta depende também da identidade das cinases/fosfatases, e dos seus respectivos substratos, presentes nesse tipo de célula (Texto 2 ).

\begin{tabular}{|l|}
\hline Ordem do narrar \\
\hline $\begin{array}{l}\text { Recentemente, identificaram-se outros mecanismos reguladores mais } \\
\text { sofisticados }\end{array}$ \\
\hline
\end{tabular}

que determinam onde e quando as proteínas cinases e fosfatermotases são activadas na célula. As subunidades catalíticas das cinases e fosfatases raramente ocorrem livres na célula, mas sim associadas a outras proteínas que controlam a sua actividade (chamadas proteínas esqueleto, proteínas de ancoragem e proteínas adaptadoras). A existência de proteínas esqueleto, de ancoragem e adaptadoras contribui para a especificidade dos processos de transdução de sinais ao recrutar enzimas activas para redes de sinalização ou ao colocá-las na proximidade dos seus substratos. $[\ldots]$

\section{Quadro n. ${ }^{\circ} 4$}

Também o Texto 2. B abre com discurso teórico - podendo observar-se, neste caso, a particularidade da construção de um destinatário que não coincide com o interlocutor (ou leitor empírico (o leitor sem qualquer formação em Química é equivalente a [qualquer leitor sem qualquer formação em Química]). Por outro lado, observa-se que o discurso teórico é entrecortado por segmentos da ordem do narrar - como mostra o Quadro n. ${ }^{\circ} 5$. 


\section{Ordem do expor}

Mesmo para o leitor sem qualquer formação em Química palavras como catálise, catalisadores e outras daí derivadas, não lhe são estranhas por já terem entrado no léxico corrente do cidadão minimamente educado. É frequente um alto dirigente afirmar num seu discurso que as medidas que tomou numa dada área específica irão catalisar o desenvolvimento de todo o seu sector; um escritor afirmará que uma dada experiência pessoal catalisou toda a escrita do seu novo romance; etc., etc., etc.

Se estes termos começaram a ser correntes na linguagem comum (perdendo simultaneamente o seu significado preciso), isso reflecte, até certo ponto, a sua importância, pela realidade que descrevem, na área científica e tecnológica de onde foram apropriados: a ciência e a tecnologia químicas e a sua utilização na indústria química.

\begin{tabular}{|c|c|}
\hline & $\begin{array}{l}\text { A expressão força catalítica foi cunhada, em 1835-36, pelo famoso químico } \\
\text { sueco Jöns Jakob Berzelius, para descrever o comportamento de certas } \\
\text { substâncias que «eram capazes de, pela sua simples presença, que não } \\
\text { pela sua afinidade própria, acordar (noutras substâncias) afinidades que } \\
\text { (àquela temperatura) estavam dormentes». } \\
\text { Sessenta anos depois, em 1895, Friedrich Wilhelm Ostwald, químico-físico } \\
\text { alemão de origem russa, a quem, em 1909, foi atribuído o Prémio Nobel } \\
\text { pelos seus trabalhos sobre catálise, equilíbrio químico e velocidade das } \\
\text { reacções, definia catalisador como uma substância que altera a velocidade } \\
\text { de uma reação química sem modificar os factores energéticos dessa } \\
\text { reacção, definição a que o próprio Ostwald deu, em 1902, uma nova forma: }\end{array}$ \\
\hline
\end{tabular}

substância que altera a velocidade de uma reacção química sem aparecer como produto final dessa reacção.

Esta definição tem-se mantido praticamente inalterada e, em 1976,

a IUPAC - International Union of Pure and Applied Chemistry, a organização internacional que estabelece as regras da nomenclatura química,

definiu catálise como

um fenómeno no qual uma quantidade relativamente pequena de uma substância estranha, chamada catalisador, aumenta a velocidade de uma reacção química sem que ela própria seja consumida nessa reacção.

\section{Quadro.$^{\circ} 5$}

O primeiro segmento narrativo, mais longo, apresenta as noções/os termos em causa numa perspetiva histórica, através do recurso aos localizadores temporais e aos tempos gramaticais em ocorrência (assinalados com negrito no Quadro n. ${ }^{\text { }}$ ). Trata-se, portanto, de situar as noções/os termos na sua própria história e na história da ciência - o que significa, em última análise, que o discurso da ordem do narrar está aqui ao serviço da atitude expositiva dominante. É o que também parecem confirmar os outros brevíssimos segmentos narrativos, em que voltamos a observar um movimento de contaminação: 
- a ocorrência do pretérito perfeito composto (tem-se mantido), marcando a inclusão do momento de enunciação, fecha (com a chegada ao presente) o percurso histórico da expressão;

- o localizador (em 1976) e a forma verbal no pretérito perfeito simples (definiu) - que se encontram numa relação de deslinearização - marcam de novo a ordem do expor;

- a conjunção dos dois aspetos permite inferir que 1976 seja globalmente entendido ou aceite como presente - relativamente ao presente da enunciação (1988 é a data da publicação do artigo, sendo a data de produção necessariamente anterior) e, também provavelmente, ao que se toma como história, numa perspetiva de evolução científica.

\section{Síntese e perspetivas de trabalho}

As análises desenvolvidas permitem evidenciar vários aspetos significativos relativamente aos textos analisados. Em primeiro lugar, podemos dizer que, nos quatro casos, parece verificar-se uma moldura estabelecida por uma atitude discursiva do expor, embora com características diferenciadas: nos Textos 1. A e 1. B, trata-se de um expor implicado, nos Textos 2. A e 2. B, de um expor (tendencialmente) autónomo. Para além dessa moldura, no entanto, há diferenças que, de acordo com a hipótese colocada, parecem decorrer do género. Assim, nos textos memorialísticos, ainda que a ordem do narrar se apresente como predominante (em termos de extensão), a articulação entre expor e narrar parece ser uma contingência do género - suscitada pelo vaivém entre presente e passado que exige o trabalho da/com a memória. Nos artigos científicos, pelo contrário, a ordem do expor é claramente dominante, como já se disse - correspondendo os segmentos da ordem do narrar a simples recursos ou suportes - para uma exposição introdutória e/ou para esclarecimentos de carácter histórico.

Importa retomar as conclusões agora esboçadas e desenvolver o trabalho de análise - com mais textos dos mesmos géneros e com textos de outros géneros. Mais do que concluir, perspetivamo-nos, portanto, em termos de trabalho a continuar.

\section{Bibliografia}

Benveniste, E. (1966): «Les relations de temps dans le verbe français». Em: Problèmes de linguistique générale, I. París: Gallimard, 237-250. 
Bronckart, J.-P. (1999): Atividade de linguagem, textose discursos: por um interacionismo sócio-discursivo (trad. de Anna Rachel Machado). São Paulo: EDUC.

Bronckart, J.-P. (2008): «Genres de textes, types de discours et «degrés» de langue». Em: Texto!, XIII, 1: http://www.revue-texto.net/docannexe/ file/86/bronckart_rastier.pdf (1-95) (01-02-2012).

Coutinho, M. A., Miranda, F. (2009): «To describe textual genres: problems and strategies». Em: Charles Bazerman, Débora Figueiredo, Adair Bonini (orgs.), Genre in a Changing World. Colorado-Indiana: Parlor Press \& WAC Clearinghouse, 35-55.

Genette, G. (1986): «Introduction à l'architexte». Em: Gérard Genette et al. (eds.), Théorie des genres. París: Seuil, 89-159.

Miranda, F. (2009): «O discurso interactivo em diferentes géneros: uma abordagem empírica». Em: Estudos Linguísticos/Linguistic Studies, 3. Edições Colibri/CLUNL: Lisboa, 365-381.

Rocha, C. (2006): «Memorialismo». Em: Biblos, Enciclopédia Verbo das Literaturas de Lingua Portuguesa, 3. Lisboa-São Paulo: Verbo, 627-634.

Silva, A. (1988): «Nota de abertura». Em: Colóquio/Ciências, 1, 2.

Simonin-Grumbach, J. (1975): «Pour une typologie des discours». Em: Julia Kristeva, Jean-Claude Milner, Nicolas Ruwet (eds.), Langue, discours, societé. Pour Emile Benveniste. París: Seuil, 85-121.

Voloshinov, V. N. ([1929] 1977): Marxisme et philosophie du langage. París: Minuit.

Vigotski, L. S. ([1934] 1997): Pensée et langage. París: La Dispute.

Weinrich, H. (1973): Le temps. París: Seuil.

\section{Textos analisados}

Azenha, J. (texto inédito): As minhas memórias. Texto redigido entre 2006 e 2007. Dias, A. R. (1988): «Catálise e catalisadores». Em: Colóquio/Ciências, 3, 31-48. Saramago, J. (2006): As pequenas memórias. Lisboa: Caminho.

Silva, E. (1998): «As fosfatases e a linguagem intracelular». Em: Colóquio/ Ciências, 22, 43-56. 


\section{CATÁLISE E CATALISADORES}

Setenta por cento dos processos industriais envolvendo reaccões químicas recorrem a catalisadores e $90 \%$ dos novos processos desse tipo são catalíticos. Cerca de 3,4 millbões de toneladas de producão anual da indústria portuguesa, no valor de 85,4 milbôes de contos, são obtidos através de tecnologias catalíticas.

\section{ALBERTO ROMÁO DLAS}

$\mathbf{M}$ esmo para o leitor sem qualquer formação em Quimica palavras como catálise, catalisadones e outras dai derivadas, não lhe são estranhas por já terem entrado no léxico corrente do cidadāo minimamente educado. E frequente um alto dirigente afirmar num seu discurso que as medidas que tomou numa dada área específica irāo catalisar o desenvolvimento de todo o seu sector; um escritor afirmará que uma dada experiência pessoal catalisou toda a escrita do seu novo romance; etc., etc., etc.

Se estes termos começaram a ser correntes na linguagem comum (perdendo simultaneamente o seu significado preciso), isso reflecte, até certo ponto, a sua importância, pela realidade que descrevem, na área científica e tecnológica de onde foram apropriados: a ciência $\mathrm{e}$ a tecnologia químicas e a sua utilização na indústria química.

A expressão força catalitica foi cunhada, em 1835-36, pelo famoso químico sueco Jöns Jakob Berzelius, para descrever o comportamento de certas substâncias que "eram capazes de, pela sua simples presença, que não pela sua afinidade pröpria, acordar (noutras substâncias) afinidades que (äquela tempenafuna) estauam domentes"

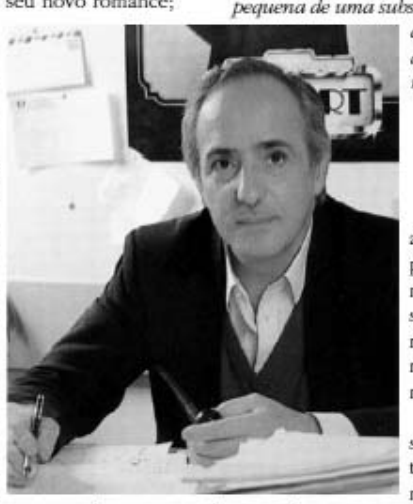

Licenciado em Engenharia pelo Instituto

reacção, definiçâo a que o próprio Ostwald deu, em 1902 uma nova forma: substância que altera a velocidade de uma reaçāoo química sem aparecer como produto final dessa reacçâo.

Esta definiçāo tem-se mantido praticamente inalterada e, em 1976, a IUPAC - International Union of Pure and Applied Chemistry, a organização internacional que estabelece as regras da nomenclatura química, definiu catalise como um fenómeno no qual uma quantidade relativamente pequena de uma substância estranba, chamada catalisador, Sessenta anos depois, em 1895 . Friedrich Wilhelm Ostwald, quimico-físico alemāo de origem russa, a quem, em 1909, foi atribuido o Prémio Nobel pelos seus trabalhos sobre catálise, equilibrio quimico e velocidade das reaçoóes, definia cataFisador como uma substância que altera a vebocidade de uma neaç̧ä́ química sem modificar as factores eneryéticos dess pela Universidade de Oxford (1970), Alberto Romao Dias e professor catedratico do IST onde preside, desde 1984, ao Departamento de Engenharia Quimica. A sua fecunda e valio sa obra de investigador incide sobre Quimica organometalica de metais de transiçáo e catalise. Foi Secretario-Geral da Sociedade portuguesa de Ouimica (1979-87) e Secretario de Fstado do Ensino Superior (1982-83). Estudioso dos problemas pedagogicos e cientificos das universidades portuguesas, assume "Ciencia Tecoologia e sociedade". aumenta a velacidade de uma neacção quimica sem que ela própria seja consumida nessa reacção.

\section{REACTIVIDADE E CATÁUSE}

Antes de entrar na descrição de alguns tipos de catalisadores e de processos catalíticos parece conveniente debruçarmo-nos um pouco sobre os factores que condicionam as reacçōes químicas incluindo os factores que afectam a velocidade dessas reacçoóes.

Consideremos, por exemplo, duas substâncias quimicas $A$ e $B$ (reagentes) que, se misturadas em determinadas condiçóes, podem reagir entre para dar origem a duas novas substâncias químicas $C$ e $D$ (produtos). Os quimicos representam esta situação de reacção química através, da escrita de uma equação química.

Se o interesse ao juntar A e B obter C e D temos de fazer um estudo que responda às seguintes perguntas: 


\section{AS FOSFATASES E A LINGUAGEM INTRACELULAR}

A fosforilação reversivel de proteínas é utilizada como a principal linguagem intracelular para transduzir sinais do ambiente celular. Dado ser geralmente reconhecida como a principal modificação pós-traducional existente nas células eucarióticas, não admira que algumas das mais importantes patologias humanas estejam associadas à fosforilação anormal de certas proteínas chave (e.g. o cancro, a diabetes e a doença de Alzheimer). O papel central das fosfatases específicas para serina e treonina no controlo da fosforilação proteica, e como alvos potenciais de diversas toxinas e toxicantes ambientais, identificam-nas como objectos valiosos de investigação.

\section{EDGAR F. DA CRUZ E SILVA}

$\mathrm{O}$ ermo transdução de sinais refere-se à transferência de informação através da membrana celular, isto é, à deteccầo de um sinal extracelular, respectiva transformaçào noutro sinal intracelular, e sua propagação. A transdução de sinais é um componente essencial da regulaçào celular. Por exemplo, várias moléculas bioactivas, das quais as hormonas e os neurotransmissores são os exemplos melhor conhecidos, estào acopladas às suas vias de sinalizaçào intracelular através de receptores membranares (Fig, 1). As cascatas de sinalização sào iniciadas por primeiros mensageiros (hormonas, neu rotransmissores ou drogas, por exemplo) que passam a sua informaçào ao compartimento intracelular através de receptores membranares que, por sua vez, levam à produçào de segundos mensageiros (por exemplo, cálcio e cAMP). Estes segundos mensageiros vào por sua vez activar os seus 'receptores' intracelulares específicos, normalmente cinases $\mathrm{e} / \mathrm{ou}$ fosfatases, resultando na fosforilação/desfosforilação de determinadas proteínas e levando ao correspondente efeito celular. Muitas vias de sinalização resultam na alteração do estado de fosforilaçào de resíduos dos aminoácidos serina, treonina ou tirosina nas proteínas alvo. Num dado tipo de célula, estes sistemas de integraçâo e modificação de sinais podem-se manifestar a vários níveis. Assim, à superficie celular, a funçào dos receptores e dos transportadores de neurotransmissores pode ser regulada por fosforilaçào. A fosfori-

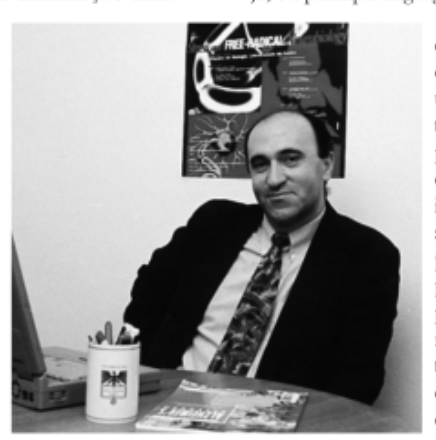

Depois de frequentar o Lisceu Nacional de Gil Vicente (Lisboa), Fdgar F, da Cruz e Silva obteve o grau de B.SC. na Universidade de Essex (Inglaterra) e o grau de Ph.D. em Bioquimica ma Universidade de Dundee (Escócia). A sua carreira cientifica continuou com estudos sobre as fosfatases especificas para serina etrenina na Lnivessidide de Dundee ena Liniendade Rockefeller em Nova lorque (ELA). Regressou recentemente a Portugal, depós de vinte anos no estrangeiro. E Professor Associado Convidado na do residate de Averio e Coordenador Cientifico do recém criado Centro de Biologia Celular. E autor de diversas publicaçoes em revistas interna-

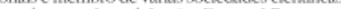
Programa de Neurotoxicologia dos Partner "do Programa de Neurotoxicologia dos Centers for

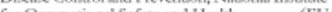

laçào proteica regula também uma variedade de processos intracelulares chave, como, por exemplo, a liregulando a transcrição génica através da fosforilação de controlam certas respostas celulares. Em conclusiato, a fosforilação de proteinas representa uma via final comum de sinalização celular, ou sede comunicação celular

O facto da fosforilação proteica estar envolvida em muitos aspectos de sinalizaçào celular nào implica uma falta de especificidade. Pelo contrário, embora as cinases, e principalmente as fosfatases, exibam pouca especificidade para os seus substratos in vitro, na célula intacta elas possuem um elevadíssimo grau de especificidade. Assim, o mesmo sinal pode não só produzir diferentes respostas em células diferentes, mas até na mesma célula, dependendo do estado metabólico desta. A especificidade é adquirida e mantida através de variadas estratégias. O tipo de receptores membranares que uma dada célula expressa, num determinado espaco temporal, define as moléculas capazes de desencadear uma resposta celular. Por outro lado, a natureza dessa resposta depende também da identidade das cinases/fosfatases, e dos seus respectivos substratos, pre. sentes nesse tipo de célula (Fig, 2).

Recentemente, identificaram-se outros mecanismos reguladores mais sofisticados que determinam onde e quando as proteínas cinases e fosfa- 
Maria Antónia Coutinho, Noémia Jorge

New University of Lisbon, CLUNL, FCT

\section{Text genre and time discursive construction}

Keywords: text genre, discourse type, expositive order, narrative order

This paper adopts a text and discourse linguistics framework. We will assume discourses (or discourse types) represent an intermediate organizational level between text genre and the specific linguistic devices in use (Bronckart, 1997, 2008). Discourse types play a key role in language activity, as they allow the transition between individual and collective representations, and they involve temporal and agentive relationships. In our research, we focus the linguistic devices associated with temporal relationship, in order to distinguish between expositive and narrative discourses and to verify our main research issue: to understand how social activity and text genre can constrain the presence of different discourse types and to describe what function can assume the same discourse type in different texts (of different genres). To obtainn evidence to address these questions, we analyze texts produced in literary, familiar and scientific activities. 
Maria Antónia Coutinho, Noémia Jorge

Nova univerza v Lizboni, CLUNL, FCT

\section{Besedilna zvrst in diskurzna sestava časa}

Ključne besede: besedilna zvrst, tipi diskurza, ekspozitivni red, narativni red

Prispevek se umešča v področje besediloslovja in lingvistike diskurza ter predpostavlja obstoj diskurzov (ali tipov diskurza) kot vmesne organizacijske ravni med besedilno zvrstjo in uporabljenimi jezikovnimi sredstvi (Bronckart, 1997, 2008). Tipi diskurza predstavljajo semiotičen izraz »diskurznih svetov« in igrajo ključno vlogo $\mathrm{v}$ jezikovni dejavnosti, ker omogočajo prehod med individualnimi in kolektivnimi predstavami. Diskurzni svetovi nastajajo v funkciji dveh psiholoških operacij, ki vključujeta čas in vršilce dejanja. Avtorici prispevka se posvečata časovni organizaciji (in ustreznim jezikovnim sredstvom) ter dokazujeta, da je ta pomembna za razlikovanje ekspozitivnih od narativnih diskurzov. Želita preveriti, v kakšni meri socialna dejavnost in besedilna zvrst omejujeta prisotnost različnih diskurznih tipov, ter odkriti, katera funkcija lahko prevzame isti tip diskurza v različnih besedilih (zvrsteh). Da bi prišli do podatkov za vsa ta vprašanja, analizirata književna, pogovorna in znanstvena besedila $\mathrm{v}$ dveh različnih besedilnih zvrsteh (spomini, znanstveni članki). Na podlagi te analize dokazujeta obstoj ekspozitivnega diskurznega okvira $\mathrm{v}$ obeh besedilnih zvrsteh in ugotavljata, da se narativni segmenti $\mathrm{v}$ znanstvenih člankih nahajajo le $\mathrm{v}$ uvodnih sekcijah ali pri zgodovinskih razlagah, medtem ko so za spomine, ki so odvisni od nihanja med preteklostjo in sedanjostjo, ti segmenti značilni in veliko bolj pomembni. 